energy in disturbances evidently of equatorial origin when they reach the Pacific coast of the United States and the coast of Spain. Unless the direction of the zone of high pressure along the south margin on which they move forms an angle of more than forty-five degrees with the equator, the storm has a tendency to pass through it, and in doing so expends much of its energy.

(To be continued.)

JEROME J. COLLINS

\section{GAS AS FUEL}

A TTEMPTS have been made from time to time to use gas as a means for heating; these attempts have more frequently failed than stcceeded, chiefly by reason of the mechanical difficulties to be overcome.

It is pretty generally agreed that, on account of the ease with which the supply of a gaseous fuel can be regulated, the completeness with which such a fuel can be burned, the comparative readiness with which cleanliness can be maintained while using this fuel, and by reason of its high heating power, and for other reasons, gaseous fuel is to be much preferred to fuel in the solid form.

The most perfect gas for heating purposes would be that, the constituents of which should be all combustible, should be possessed of high thermal powers, and should produce, on burning, compounds of small specific heat. No gas which has yet been produced for use as fuel completely fulfils these conditions.

Common coal-gas contains such non-combustible bodies as carbondioxide and nitrogen, and among the products of its combustion is water, a body of large specific heat, and also requiring a considerable amount of heat to convert it into vapour. The complete combustion of coal gas also necessitates a comparatively large supply of air, and this, again, involves special mechanical appliances. Nevertheless, coal-gas has been proved to be, for certain purposes, a cheaper, more effective, and more easily managed fuel than coal, wood, or other forms of solid heat-giving material.

That steam is decomposed by hot carbon with the production of a gaseous mixture of considerable heating powers, has long been known, and several attempts have becn made to utilise the products of this decomposition. These attempts bave met with no great success on account of the cost of the plant required to work the manufacture and of the difficulties of the process. Long-continued experiments have, however, been carried on, and it would appear from a paper recently communicated to the Society of Arts by Mr. S. W. Davies, that these experiments have been crowned with a very fair measure of success.

The great difficulty was a mechanical one: it has been very simply overcome. Superheated steam is produced in a coil placed within a cylinder and is driven by its own tension in the form of a jet into the lower part of an anthracite fire. The jet of steam carries with it air sufficient to actively maintain the combustion of the anthracite; the gases issue at the top of the apparatus and pass into the mains. The fire is fed from the top by an arrangement which allows of the process being continuous. Water is forced into the coil under a pressure varying from $\mathrm{I} 5 \mathrm{lbs}$. to $40 \mathrm{lbs}$. on the square inch. The whole apparatus is compact and simple.
The products of the decomposition of steam by hot carbon are mainly hydrogen and carbon monoxide; traces of marsh gas are also formed. Could these gases be produced free from admixed non-combustible bodies we should have a gas of very high heating powers. But the temperature of the glowing carbon must be maintained by the introduction of oxygen, that is, in practice, by the introduction of air. The problem how to introduce air sufficient to keep up vigorous combustion, and at the same time to maintain the decomposition of the steam, appears to have been satisfactorily solved; but the introduction of air means a lowering of the heating power of the gas produced, inasmuch as four volumes of nitrogen are brought in along with every volume of oxygen supplied. By passing the gas through a series o vessels containing hot carbon the nitrogen may be very much diminished in amount, and the heating power of the gas proportionally increased.

The gas produced by the decomposition of steam by hot carbon always contains traces of carbon dioxide which is non-combustible; the amount of this compound may, however, be reduced to 3 or 4 per cent. by regulating the depth of the layer of hot carbon through which the gases pass, and by maintaining the temperature of that carbon at a high point. But the maintenance of a high temperature throughout a mass of carbon can be accomplished, under the conditions of the manufacture, only by introducing a rapid current of air, which again means a dilution of the gas produced.

If, therefore, means could be found forefeeding the anthracite fire with oxygen, a gas of very high heating power might be: produced. A supply of oxygen at a cheap rate is a great desideratum; the gas exists in practically unlimited quantity in the atmosphere, but an easy and successful method for separating it from the nitrogen with which it is there mixed is still only hoped for by the chemical manufacturer. Were a supply of oxygen forthcoming, mechanical difficulties would present themselves before it could be utilised in the production of "water gas." The introduction of too small an amount of oxygen would mean the non-decomposition of the whole of the steam and the cessation of the combustion of the anthracite; the introduction of too much oxygen would mean the production of carbon dioxide in considerable quantity. But by regulating the size of the steam jet and of the blast-pipe, these difficulties might probably be overcome.

As the gas is now produced all danger of explosion is removed.

The heating effect of the gas as at present manufactured is about one-fifth that of ordinary coal-gas, for equal volumes; but the cost of the gas is so much less than that of coal-gas, that a given amount of heating work may be done-according to the figures given in the paper referred to-by using the new gas, with a saving of from one-third to two-thirds of the expenditure which would be involved were coal-gás employed.

Although the new gas is not perfectly adapted for the purposes for which it is to be used, yet there can be little doubt that we are now a step, and a very considerable step, nearer the final solution of the problem. Doubtless improved furnaces, and improved apparatus generally for burning the improved fuel, will be introduced. 
The production of a cheap gaseous form of fuel is a great gain; so also is the invention of a means whereby the large stores of anthracite coal in this and other countries can be utilised.

Of all the forms of carbon experimented with in the production of the new gas, anthracite was found the best. Anthracite is difficult to burn; the ordinary forms of furnace do not admit of such a complete oxidation as is required in order to maintain the combustion of anthracite. But the blast of air carried into the gas generator of the water-gas apparatus by the steam jet insures the presence of a large quantity of oxygen, and therefore the combustion of the anthracite. Whether a simpler means could not be adopted for the combustion of anthracite is a question worthy of consideration. That a steam jet can be thrown into an ordinary furnace charged with anthracite, and the combustion of the coal be thereby insured, has been shown to be possible. Nevertheless, the production of combustible gas from she anthracite is to be preferred, for many reasons, to the consumption of the solid fuel.

The fact that we shall soon probably be in a position to make use of our stores of anthracite, is one of very considerable importance from an economic point of view. In possessing large quantities of anthracite we possess a a valuable commodity, but if we cannot realise a use for that commodity it ceases to be a source of wealth to us.

Further, large quantities of anthracite are known to exist in some of the British Colonies and in the United States; the utilisation of these would mean an increase in the commercial enterprises owned by Englishmen abroad, or supported by English capital; it would also probably imply an increase in the tonnage of shipping, and wrould thus tend to increase our "international wealth."

Whether it be regarded from the point of view of the chemist, or of the economist, the introduction of a cheap gaseous fuel manufactured from anthracite, marks a point of no little importance in the advance of manufacturing industries.

The experiments detailed in the paper by Mr. Davies show that the new gas is especially adapted for use in cooking :operations in large private establishments, in clubs, hotels, barracks, \&c. It is known that cooking can be more cheaply and more rationally conducted with the aid of gaseous than of solid fuel; if the new fuel does all that it promises to do, judging from the actual trials already made, its introduction will be welcomed by the artistic cook noless than by the scientific chemist, and by the political economist. M. M. PATTISON MUIR

FOSSIL FLORA OF GREAT BRITAIN

The Fossil Flora of Great Britain; or, Figures and Descriptions of the Vegetable Remains Found in this Country.

Illustrations of Fossil Plants, being an Autotype Reproduction of Selected Drawings prepared under the Supervision of the late Dr. Lindley and the late Mr. William Hutton, between the Years $\mathrm{I} 835$ and $\mathrm{I} 840-$ and now for the first time published by the North of England Institute of Mining and Mechanical Engineers. Edited by G. A. Lebour, F.G.S. (Newcastle-upon-Tyne, I 877 .) 7 HE publication, in $183 \mathrm{I}$, of the first number of the l "Fossil Flora of Great Britain," by Dr. Lindley and William Hutton, marked the beginning of a new era in the history of English Palæo-phytology. Much had been previously done on the Continent. The magnificent Flora der Vorwelt of Sternberg had laid a solid foundation for such studies, and the Vegétaux Fossiles of Adolphe Brongniart, then in progress of publication, was not only widening those foundations, but was systematising the study, as his "Prodrome" had developed the first principles of the philosophy of the primaval Flora. The late Professor Phillips had further recorded additional discoveries amongst the Oolitic plants of Yorkshire, in his "Geology of the Yorkshire Coast"; but there yet remained a wide field for exploration, especially amongst the plants of the Carboniferous age, in which England was especially rich; and Phillips and Brongniart were very far from having exhausted the newly-discovered plants of the Yorkshire Oolites. Hence when the two able authors above named commenced the publication of their "Fossil Flora," they found a vast mass of new materials awaiting their investigation. In endeavouring to estimate the true value of their work, we must not regard it from our present standpoint, but from that of the time at which they began their labours. At that period, though collections of fossil plants were numerous, they were scattered over the country in isolated cabinets, and no one knew much about what those cabinets contained. Hence the first work demanding attention was to ascertain what the forms and general relations of these fossil plants were, and the pages of the "Fossil Flora" gradually gave the needful information so far as it was then obtainable. The two authors named figured and described such distinct fragments as fell into their hands, and thus made available for the students of a later period a vast mass of hitherto unknown material. This important publication went on for several yearsbut at length the two authors became weary of their costly venture. The number of persons actively interested in the study of fossil plants was not sufficiently great to cover the expense of the publication, which consequently came to an abrupt end. In 1839 the late Dr. Lindley told the writer of these lines that he saw no reason why he should employ his purse for the benefit of the geologists who failed to give him the needful support, and he acted upon the conviction thus expressed.

In endeavouring to measure the true value of the work of Lindley and Hutton to modern science, we must not forget the date of their labours. At the earlier part of the time when the publication of the "Fossil Flora" was in progress, little or nothing was known of the internal organisation of any fossil plants. But at length two instructive fragments were obtained in England-one of a Lepidodendron, and the other of a Stigmaria-both of which examples revealed a measure of minute internal organisation. Witham's "Observations on Fossil Vegetables," published in 1831, contained figures and descriptions of the first of these specimens, the now well-known Lepidodendron Harcourtii, and the Stigmaria was figured and described in the "Fossil Flora." These two specimens were the beginnings of a rich harvest, which is even yet but very partially reaped, but which has already prepared the way for a revolution in the processes and results of Palæo-phytological studies. But though the authors of the "Fossil Flora" thus obtained some glimpses into the possible future of their science, 